\title{
OS ATOS DE FALA EM MAITENA: SUPERADAS
}

The speech acts in Maitena: Superadas

\author{
Thiago de Sousa Amorim ${ }^{1}$ \\ Iveuta de Abreu Lopes ${ }^{2}$
}

RESUMO: O presente estudo tem como objetivo analisar os atos de fala em Maitena: Superadas. Para concretizar a investigação tomaram-se como base teórica os estudos de Lopes (1989), Cardoso; Mengarda (2011), Fiorin (2008), Souza Filho (2006), entre outros trabalhos que se fizeram necessários. A pesquisa foi de base qualitativa e indutiva, à medida que se buscou interpretar os quadrinhos de Maitena: Superadas, como forma de testar as categorias de análise da Teoria dos Atos de Fala, que são os atos locucionários, ilocucionários e perlocucionários. A análise apontou que simples sentenças presentes em quadrinhos são eivadas de significação e ação dentro do alcance da Teoria dos Atos de Fala, na perspectiva da Pragmática. Portanto, pôde-se concluir que a Pragmática, atrelada aos Atos de Fala, possibilita um olhar mais apurado sobre o significado linguístico a ser interpretado por um contexto extralinguístico em dada sentença.

Palavras-chave: Pragmática. Atos de fala. Maitena: Superadas.

ABSTRACT: The present study aims to analyze the speech acts in Maitena: Superadas. In order to carry out the research, the studies of Lopes (1989), Cardoso; Mengarda (2011), Fiorin (2008) and Souza Filho (2006) were taken as theoretical basis, among other works that became necessary. The research was qualitative and inductive, as it was sought to interpret the comics of Maitena: Superadas, as a way of testing the categories of analysis of the theory of the Acts of Speech, which are the locutionary, illocutionary and perlocutionary acts. The analysis pointed out that simple sentences present in comics are imbued with meaning and action within the scope of speech acts theory, from the perspective of Pragmatics. Therefore, it was concluded that Pragmatic, linked to speech acts, allows a more accurate look at the linguistic meaning to be interpreted by an extralinguistic context in a given sentence.

Keywords: Pragmatic. Acts of speech. Maitena: Superadas.

\footnotetext{
${ }^{1}$ Graduado em Letras - Espanhol (UESPI). Especialista em Linguística, Literatura e Ensino (IESM). Mestrando em Letras - Estudos da Linguagem (UFPI). E-mail: tyagoamorim25@hotmail.com

2 Doutora em Letras (UFPE). Professora do Programa de Pós-Graduação em Letras (Estudos da Linguagem), da Universidade Federal do Piauí (ÚFPI). E-mail: iveuta@uol.com.br
}

Cadernos Cajuína, V. 4, N. 1, 2019, p.282 - 293.

ISSN: 2448-0916 


\section{CONSIDERAÇÕES INICIAIS}

A Teoria dos Atos de Fala é uma das principais vertentes da Filosofia da Linguagem que tem por finalidade realizar estudos pragmáticos da linguagem. Nesse caminho, estudar quadrinhos é um meio pelo qual nos deparamos com diversas situações de comunicação, cabíveis a uma análise linguística, envolvendo, sobretudo, a Pragmática.

Dentro da Pragmática, destacamos os Atos de Fala, uma teoria que, apesar de subsidiar diferentes áreas, como a Psicologia, a Crítica Literária, a Antropologia e a Filosofia, acarreta uma importância fundamental à Pragmática, de modo a aferir contribuições louváveis aos estudos que envolvem a linguagem, como propulsora de produção de sentido em enunciados de determinadas situações comunicativas.

Ao considerar antecedentes de pesquisa, podemos inferir, indistintamente, que são escassas as pesquisas que, porventura, versem sobre a Teoria dos Atos de Fala em quadrinhos de Maitena, apreciando as diferentes produções do gênero por parte da autora, como: Mujeres alteradas, Lo mejor de Maitena, Superadas e Lo peor de Maitena. Assim, o presente trabalho pretende analisar os atos de fala em quadrinhos de Maitena: Superadas.

O corpus foi selecionado do site oficial da escritora, em que, boa parte de sua produção está disponível para download. Maitena Burundarena tem nacionalidade argentina, nascida na região rio-platense, na localidade de Bela Vista. A autora é de descendência vasca por parte de Carlos Burundarena, seu pai, e polaca, por parte de Janina Streb, sua mãe. Desde algum tempo, Maitena vem reinventando o seu mundo artístico. Tem uma vasta produção de quadrinhos cômicos, tendo produzido livros, também. Dentre suas obras estão: Mujeres Alteradas; Superadas; Curvas peligrosas; Rumble.

O gênero quadrinho é vestido de características, como marcas que direcionam críticas sobre determinados costumes e sobre determinada moral de época, ao lado de outros gêneros humorísticos. O quadrinho é capaz de criar situações fictícias, mas baseadas em fatos que se aproximam da realidade cotidiana. Assim, podemos inferir que Maitena, em muitas de suas produções, estabelece críticas, por meio de ironia e sarcasmo, à sociedade machista.

Este trabalho possui a seguinte estrutura textual: no tópico 1, fizemos uma breve introdução sobre o que trata a pesquisa; no tópico 2, fizemos uma Cadernos Cajuína, V. 4, N. 1, 2019, p.282 - 293. 
aproximação teórica a respeito da Pragmática e da Teoria dos Atos de Fala; no tópico 3, fizemos a análise de 4 (quatro) quadrinhos de Maitena: Superadas, sob o viés dos atos de fala; e, por último, as considerações finais, no tópico 4.

\section{NOÇÕES TEÓRICAS: A PRAGMÁTICA E A TEORIA DOS ATOS DE FALA}

A Teoria dos Atos de Fala está ancorada na esteira da Filosofia da Linguagem, que em sua existência tinha como objetivo analisar problemas filosóficos através da linguagem. Atualmente, é a área que concebe, da melhor forma, a percepção pragmática da linguagem.

Saussure dizia que o verdadeiro objeto da Linguística era a língua e,
para ele, a língua era a linguagem menos a fala, ou seja, menos o
uso concreto da linguagem. A Pragmática não confere à língua uma
posição central nos estudos linguísticos, não a vê isolada da
utilização da linguagem. (FIORIN, 2008, p. 166)

Com esta citação, pudemos observar que não havia um interesse em se estudar o uso da linguagem na perspectiva saussuriana. Na dicotomia língua e fala, a primeira era considerada o objeto de estudo da Linguística, sobretudo pela necessidade de se haver essa delimitação com a finalidade que a Linguística se tornasse uma ciência, de fato. A segunda, até então ficou relegada, não por desmerecimento, mas por uma escolha epistemológica de Saussure, uma vez que defendia a necessidade da constituição de uma vertente teórica para se estudar a fala, mas que não seria ele a fazer isso.

Assim, com a evolução da Ciência da Linguagem, foram surgindo novas vertentes teóricas, com a Pragmática, que visou à linguagem em uso, o que fora deixado de lado, até então. Sobre a importância de se estudar o uso da linguagem, Fiorin (2008, p. 166) assevera que: "é absolutamente necessário, pois há palavras e frases cuja interpretação só pode ocorrer na situação concreta de fala [...] é necessário também estudar o uso porque na troca verba comunicamos muito mais do que as palavras significam".

Nesse caminho, Fiorin (2008, p. 166) verbaliza que a Pragmática é uma ciência que "[...] estuda as condições que governam a utilização da linguagem, a prática linguística”. Assim, depreende-se que ela, em seu sentido latu, ambiciona dar 
conta dos usos da linguagem, condicionados por intermédio da prática concreta da língua no contexto comunicativo.

Com as palavras de Cardoso; Mengarda (2011), entende-se que a Pragmática tem por finalidade descrever e explicar o que há de interação social entre os homens, no que diz respeito à língua, nas suas mais diversas intenções de comunicação. Paralelo a isso, os autores mostram que, nas teorias referentes à Pragmática e a outras perspectivas teóricas da Ciência da Linguagem, há uma interface da língua com fatores externos a ela.

Cardoso; Mengarda (2011, p. 4) destacam que:

[...] obedecemos a escolhas e restrições de interpretação facultadas pela situação particular em que nos encontramos; recorremos ao conhecimento de regras e princípios que regulam a língua em situação de uso, que estão para além do conhecimento da língua.

Para tanto, na Pragmática, tem-se a relação entre a estrutura e o uso da linguagem. Com esse ponto de vista, vê-se que há determinadas situações em que se necessita, mesmo que se esteja dentro de regras gramaticais, de se analisar o contexto situacional (os fatores externos à língua), para que se possa estabelecer uma compreensão do enunciado.

A Teoria dos Atos de Fala foi elaborada, inicialmente por Austin (1962) e desenvolvida posteriormente por Searle $(1969 ; 1979)$. Austin parte da teoria pragmática de Wittgenstein, de que é o uso das palavras em diferentes interações linguísticas que emana sentidos. Para a compreensão da realização de atos, tem-se a noção de sentenças performativas, que na visão de Souza Filho (2006, p. 221) objetiva:

[...] denominar as concepções da pragmática que consideram o significado como determinado pelo uso e acrescentam à consideração do contexto a ideia de que a linguagem é basicamente uma forma de realização de atos e não apenas de descrição do real, sendo que a descrição do real pode ser ela própria um ato de um determinado tipo, por exemplo o ato de dar uma informação [...].

Com a ideia das sentenças performativas, contrapõe-se à das constatativas, que tem como função retratar, descrever uma realidade, enquanto que as primeiras, têm como função desencadear ações, a partir de um enunciado, numa dada situação de comunicação. Nesse sentido, Lopes (1989, p. 90) apresenta condições 
de felicidade, propostas por Austin, para que uma sentença performativa possa se materializar:

1. a) Deveria haver um procedimento convencional que tivesse um efeito convencional;

b) As circunstâncias, bem como os agentes executores deveriam ser apropriados.

2. O procedimento deveria ser executado correto e completamente.

3. As intenções das pessoas deveriam ser especificadas no procedimento e, em isto ocorrendo, as partes deveriam executá-lo.

Essas são as categorias principais, consideradas para que as condições de felicidade se realizem plenamente. Há uma dicotomia entre constatativas (verdadeiras ou falsas) e performativas (bem ou mal sucedidas). Entretanto, Souza Filho (2006) esclarece que tal dicotomia, na ótica Austiniana, é inadequada, uma vez que ambas as sentenças possuem dimensões que se interligam.

Fiorin (2008) esclarece que ao pensar as realizações das ações do homem por meio da linguagem, Austin propõe tipos de atos de fala, que na concepção de Lopes (1989) pressupõem a linguagem como ação, quer dizer, para realizar atos.

1) Primeiro ato de fala: ato locucionário, que é a simples enunciação de uma sentença, ou seja, consiste na emissão de um conjunto de sons, organizados de acordo com as regras ortográficas da língua;

2) Segundo ato de fala: ato ilocucionário, que atribui a esse conjunto uma determinada força: de pergunta, de ordem, de oferta, de promessa, etc. Sendo realizada de duas formas: explícita (de forma clara, o que é dito na frase não tem segunda interpretação) e implícita (a mensagem da frase vai além das palavras escritas, tem significado nas entre linhas);

3) O ato perlocucionário: é aquele que se destina a exercer certos efeitos sobre o interlocutor: convencê-lo, assustá-lo, agradá-lo etc., efeitos que podem realizar-se ou não.

Continuamente, outros estudiosos revisitaram a teoria de Austin para ampliar os pressupostos sobre os atos de fala. Neste sentido, Lopes (1989) destaca o estudo de Searle (1976), em que estabelece uma classificação mais ampla dos atos propostos por Austin, especificamente o ato de fala ilocucionário.

Assim, destacam-se 5 (cinco) tipos de enunciados dentro do ato ilocucionário: 
1) atos representativos ('representatives'): onde o falante compromete-se com a verdade da proposição fazendo asserções, constatações, descrições, etc.

2) atos diretivos ('directives'): através dos quais o falante tenta levar o ouvinte a executar uma determinada ação (ex. ordenando, interrogando, etc.).

3) atos compromissivos ('compromissives'): quando o falante compromete-se com o futuro curso da ação (ex. prometendo, ameaçando, etc.).

4) atos expressivos ('expressives'): através dos quais o falante expressa seu próprio estado psicológico em relação a algo que verbaliza (ex. agradecendo, desculpando-se, etc.).

5) atos declarativos ('declaratives'): através desses atos o falante alterna o estado de alguma coisa sobre a qual exerce controle (ex. nomeando, sentenciando, etc.). (LOPES, 1989, p. 91-92, destaques da autora).

Dessa maneira, Searle (1976) desenvolve a concepção de atos de fala, sob nova direção, reelaborando a classificação dos atos de força ilocutória e de seus componentes, já propostos anteriormente. Com estes atos de fala, o enunciador, de certo modo, materializa o ato de falar e de agir.

Algumas pesquisas já foram realizadas pelo viés da Teoria dos Atos de Fala, utilizando quadrinhos como corpus de análise. Nesse âmbito, podemos citar o trabalho de Cardoso; Mengarda (2011), que objetivaram analisar os componentes pragmáticos e a intencionalidade comunicativa que se manifestam em textos do gênero "tirinhas" da Mafalda. Os autores utilizam as noções teóricas sobre os atos de fala na perspectiva de Austin e chegaram ao resultado de que, tal gênero é capaz de demonstrar como a linguagem não verbal comunica profundamente, por intermédio da relação entre os atos de fala produzidos pelos locutores/interlocutores. Destacam, ainda, que a língua extrapola o literal ou o não-referencial, de forma a produzir sentidos e significações em um determinado contexto de comunicação.

Um estudo anterior ao de Cardoso; Mengarda (2011) é o de Oliveira (2009), que objetivou fazer uma análise pragmática de tiras de Mafalda, cujo é uma derivação de sua dissertação de mestrado, na qual analisa os atos de fala em alguns exemplares do gênero. Essa autora já trata sobre os atos de fala não somente na perspectiva de Austin, como na de Searle. Ela, ao analisar as tiras à luz da Teoria dos Atos de Fala, pôde depreender que, falar uma língua é realmente realizar ações e que mediante a força ilocucionária/perlocucionária as intenções do 
falante alcançam o ouvinte, a fim de que os atos propostos pelos que falem se realizem.

Silva (2007) pretendeu descrever e problematizar os conceitos básicos da Teoria dos Atos de Fala desenvolvidos por Austin, em quadrinhos humorísticos. $O$ autor chegou à conclusão de que se pode acreditar na irredutibilidade do ato ilocucionário, pelo fato de ele acontecer, também, por meio de gestos.

A partir do que foi discutido sobre os atos de fala, em uma perspectiva pragmática, nesta seção, faremos a análise dos quadrinhos de Maitena, os que foram selecionados para o presente estudo, na seção seguinte.

\section{ANÁLISE E DISCUSSÃO DO CORPUS}

Esta seção é dedicada à análise de quadrinhos de Maitena: Superadas, à luz da Teria dos Atos de Fala.

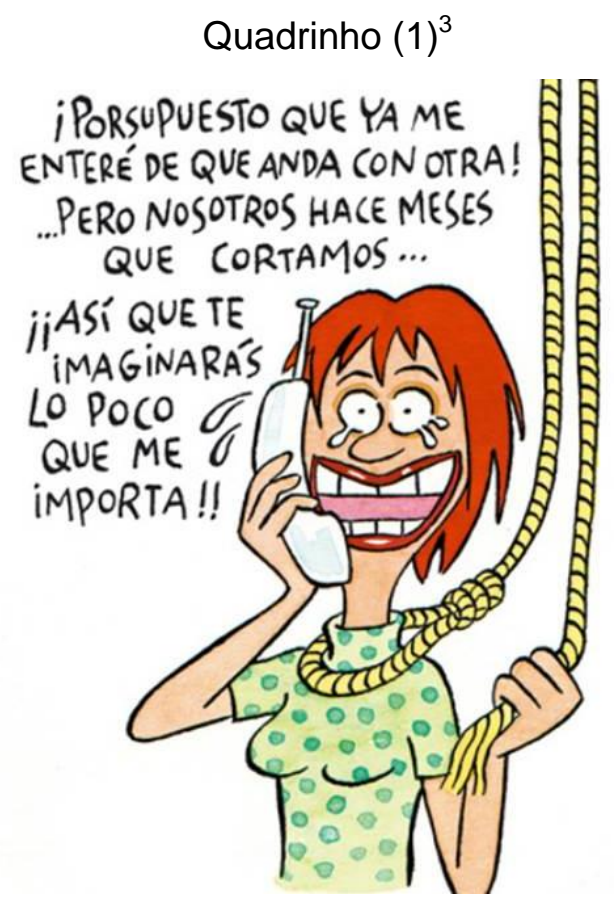

Disponível em: < http://maitena.com.ar/galerias/galeria superadas2.html >. Acesso em: 31 out. 2017.

No quadrinho (1), podemos observar que a sentenças apresentam uma estrutura dentro das regras da Língua Espanhola, o que está diretamente relacionado com o ato locucionário; há uma força ilocutória, à medida que a

\footnotetext{
${ }^{3}$ Tradução livre: "Claro que já me inteirei de que anda com outra! Mas há meses que nós terminamos. Então, você pode imaginar o pouco que me importa!".
} 
personagem faz exclamações, de forma a explicitar que já está inteirada de que o seu par está se relacionando com outra mulher, ademais de apresentar a sua inconstância com a situação. Outrossim, a dimensão perlocucionária é explicitada na reação da personagem frente aos demais atos da tirinha.

Nesse caminho, examinamos a presença do ato expressivo, por intermédio da expressão do seu estado psicológico diante da relação com seu companheiro, o que, de certa forma, faz o falante ser capaz de realizar uma determinada ação, que é a de se enforcar, no caso que está evidente na imagem, de forma a nos encaminhar para a compreensão de que há, ainda, o ato compromissivo, pelo fato de a personagem comprometer-se com uma ação futura.

Quadrinho (2) ${ }^{4}$

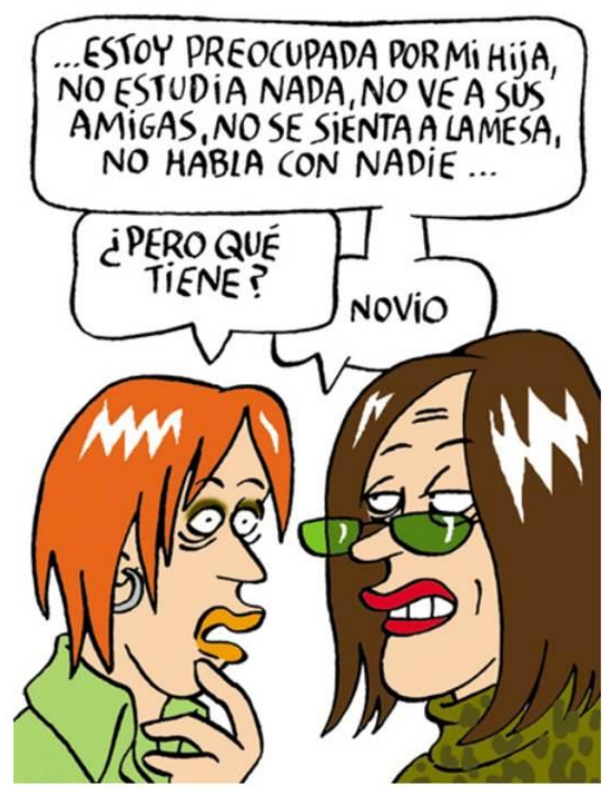

Disponível em: < http://maitena.com.ar/galerias/galeria superadas2.html >. Acesso em: 31 out. 2017.

No quadrinho (2), verificamos que o ato locucionário se materializa mediante o uso de sentenças que têm, em rigor, uma estrutura organizada na Língua Espanhola. No que diz respeito à pergunta enunciada por uma das personagens, conferimos uma força ilocucionária com relação à curiosidade de se saber o que tinha a menina por não estar realizando ações cotidianas como de costume. Já a dimensão perlocucionária se realiza à medida que a mãe tenta "convencer" a sua amiga de que tudo o que está acontecendo com a filha é porque tem um namorado.

\footnotetext{
${ }^{4}$ Tradução livre: Balão 1: “...Estou preocupada por minha filha, não estuda nada, não vê as suas amigas, não se senta à mesa, não fala com ninguém..." Balão 2: "Mas o que ela tem?" Balão 3: "Namorado".
} 
Verificamos que há a presença do ato representativo, a partir do momento em que a mãe faz asserções, mediante atitudes da filha (não estuda, não vê as amigas, não se senta à mesa, não fala com ninguém), que a levam a crer que está diferente por ter um namorado. Isto é, a personagem (mãe) faz conjecturas inferidas ou deduzidas por algo provável, baseado em presunções, pressentimentos e/ou evidências por intermédio das ações da filha.

Ressaltamos, ainda, o uso do modo indicativo, que é a marca do ato representativo, representado pelas flexões verbais do tempo presente do modo indicativo: "estou" (estoy), "estuda" (estudia), "vê" (ve), "se senta" (se sienta), "fala" (habla), "tem" (tiene).

\section{Quadrinho $(3)^{5}$}

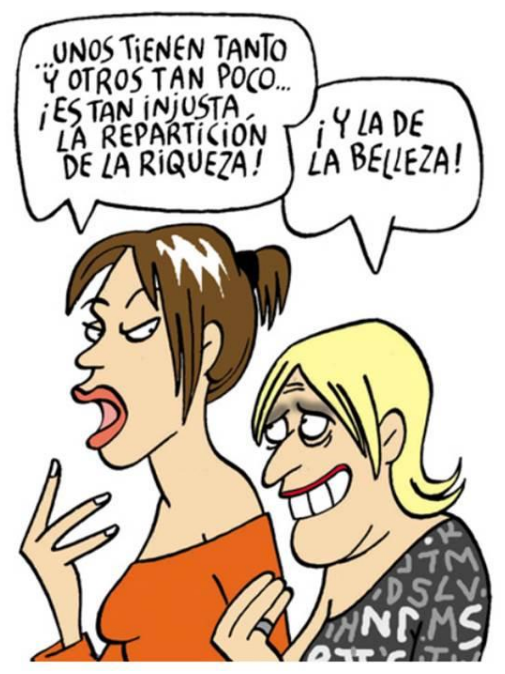

Disponível em: < http://maitena.com.ar/galerias/galeria superadas2.html >. Acesso em: 31 out. 2017.

No quadrinho (3), verificamos que o ato locucionário se manifesta por meio das sentenças organizadas conforme as regras gramaticais da língua, correspondendo a um diálogo oral entre duas mulheres. A partir de tal aparição, observamos que as ações praticadas, por via do enunciado, desencadeiam a ironia através do humor, na medida que a personagem ironizou a distribuição da beleza em comparação com a má distribuição de riqueza, o que consolida as forças ilocucionária/perlocucionária dentro do enunciado.

\footnotetext{
${ }^{5}$ Tradução livre: Balão 1: “... Uns têm tanto e outros tão pouco... É tão injusta a divisão da riqueza!". Balão 2: "E a da beleza!".
} 
Averiguamos, além disso, que há a presença do ato declarativo, ao passo que uma das personagens faz declarações críticas de cunho social sobre a má distribuição da riqueza. Para tanto, verificamos, também, o ato representativo, uma vez que percebemos a asserção de uma das personagens ao conjecturar que, além da riqueza, a beleza também possui o mesmo predicativo. Destacamos o uso dos verbos no presente do modo indicativo, que marcam os atos declarativo e representativo, que são: "têm" (tienen), "é" (es).

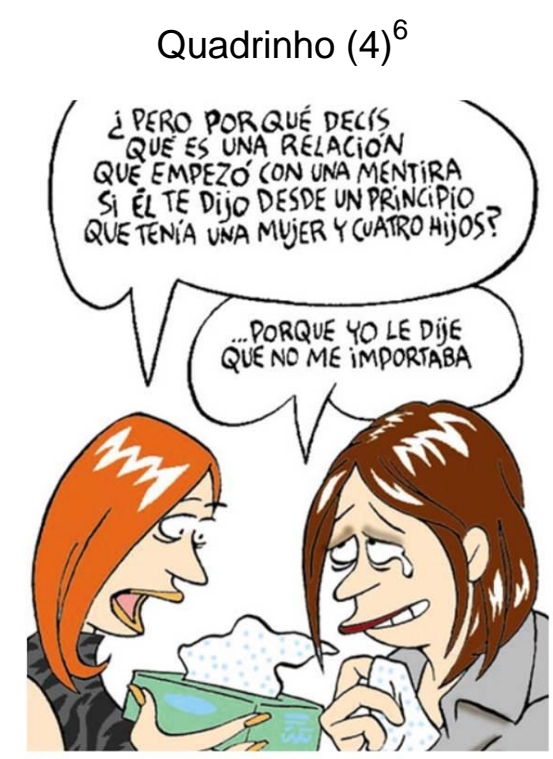

Disponível em: < http://maitena.com.ar/galerias/galeria superadas2.html >. Acesso em: 31 out. 2017.

No quadrinho (4), o ato locucionário é o próprio ato da realização de uma pergunta e de uma resposta e o ato ilocucionário é materializado pela "dúvida" da personagem em questionar a outra, sobre o fato do marido possuir uma mulher e quatro filhos. Com relação à força perlocucionária, podemos perceber, através da fisionomia de uma das personagens, que está "lamentosa", um efeito causado pela "dúvida" da outra personagem que enuncia a pergunta.

Mais uma vez, deparamo-nos com o ato expressivo, através dos quais a personagem expressa o seu próprio estado psicológico em relação a algo que verbaliza sobre si, em relação ao seu casamento.

\footnotetext{
${ }^{6}$ Tradução livre: Diálogo 1: "Mas por que você disse que é uma relação que começou com uma mentira se ele te disse desde o princípio que tinha uma mulher e quatro filhos?" Diálogo 2: "...Porque eu disse a ele que não me importava".
}

Cadernos Cajuína, V. 4, N. 1, 2019, p.282 - 293. 


\section{CONSIDERAÇÕES FINAIS}

O objetivo deste estudo foi o de analisar os atos de fala em Maitena: Superadas. Isto posto, utilizamos categorias da Pragmática que foram desenvolvidas por Austin (1962) e Searle $(1969 ; 1979)$ para podermos alcançar a nossa meta.

É sabido que o uso das palavras em diferentes interações linguísticas emana distintos sentidos. Essa concepção pôde ser notada neste trabalho, ao analisarmos os enunciados presentes nos quadrinhos, à luz da Teoria dos Atos de Fala. A análise apontou que simples sentenças presentes em quadrinhos são eivadas de significação e ação dentro do alcance da teoria, na perspectiva da Pragmática. Portanto, pudemos concluir que a Pragmática, atrelada aos Atos de Fala, possibilita um olhar mais apurado sobre o significado linguístico a ser interpretado por um contexto extralinguístico em dada sentença.

Com este trabalho, pretendemos contribuir, com o mínimo que seja, para novas propostas de estudo e incitar debates na área. A nosso ver, a Teoria dos Atos de Fala precisa ser mais explorada, por intermédio de mais investigações, para que haja uma melhor consolidação do campo teórico, dentro da cultura disciplinar ao qual está inserida.

\section{REFERÊNCIAS}

AUSTIN, John L. How to do Things with words. New York: Oxford University Press, 1962.

CARDOSO, Chayenne; MENGRADA, Elias José. Os atos de fala e intencionalidades comunicativas em quadrinhosda Mafalda. In: XII Congresso de Ciências da Comunicação, 2011, Londrina, 2011. Anais... Londrina, 2011.

FIORIN, José Luiz. A linguagem em uso. In: FIORIN, José Luiz. Introdução à Linguística I: objetos teóricos São Paulo: Contexto, 2008. p. 165-186.

LOPES, Iveuta de Abreu. 0 processo interacional em sala de aula: um estudo comparativo em dois grupos sociais. Dissertação (Mestrado em Linguística) Universidade de Brasília, Brasília, 1989.

OLIVEIRA, Mônica Lopes Smiderle de. Análise dos atos de fala nas tiras de Mafalda, Caderno do CNLF, v. XII, n. 10, p. 46-53, 2009.

SEARLE, J. R. Speech Acts. Cambridge: Cambridge University Press, 1969. 
. Expression and Meaning. Cambridge: Cambridge University Press, 1979.

The classification of illocutionary acts. Language in society. vol. 5 , núm.1, 1976, p. 1-24.

SILVA, Leosmar Aparecido da. Relação entre atos de fala e quadrinhos humorísticos. Temporis[ação], Goiás, v. 1, oㅡ 9, Jan/Dez 2007.

SOUZA FILHO, Danilo Marcondes. A teoria dos atos de fala como concepção pragmática de linguagem, Filosofia Unisinos, v. 7, n. 3, p. 217-230, set./dez., 2006. 